\title{
O porto de Imbituba na formação do complexo carbonífero catarinense
}

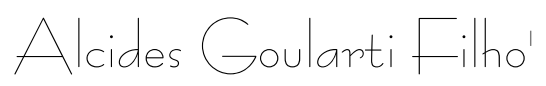

Um porto inglês na Enseada de Imbituba

Inicialmente povoada por açorianos, a localidade de Imbituba, fundada em 1715 , foi se constituindo em torno da pesca da baleia, cuja armação foi criada em 1796. Apesar de a armação baleeira ter sido extinta em 1829 , a pesca da baleia continuou sendo praticada de forma artesanal até início dos anos $1970^{2}$.

O porto de Imbituba surgiu não como uma relação direta com a pesca da baleia, e sim como parte da construção da Estrada de Ferro Dona Teresa Cristina. Ao contrário dos demais portos catarinenses, que surgiram e se desenvolveram com suas respectivas vilas, o porto de Imbituba está associado à descoberta do carvão e a partir dele que foi se formando a cidade de Imbituba.

A constatação de que havia carvão mineral no sul de Santa Catarina nos remete ao início do século XIX. Durante a primeira metade do século, a região foi visitada por naturalistas, geólogos e engenheiros que faziam análises da qualidade do mineral e recomendavam a sua exploração ${ }^{3}$.

${ }^{1}$ Univesidade do Extremo Sul Catarinense - UNESC/Curso de Economia. Pesquisa financiada pelo CNPq e FAPESC.

${ }^{2}$ MARTINS, Manuel de Oliveira. Imbituba: história e desenvolvimento. Imbituba: Editora do Autor, 1978.

${ }^{3}$ PARIGOT, Julio. Minas de carvão de pedra de Santa Catarina. Rio de Janeiro: Tipografia J. Villeneuve \& C., 1841. 
Em 1835, a Assembléia Provincial de Santa Catarina encaminhou um projeto ao governo imperial solicitando que fosse aberta uma companhia para explorar o carvão. Em 1837, Augusto Kersting também requereu junto ao governo imperial o privilégio para organizar uma companhia de mineração para explorar o carvão nas imediações de Laguna ${ }^{4}$.

O governo da província de Santa Catarina, em 1837, oficializou a descoberta do carvão em território catarinense por meio do relatório expedido pela Câmara de Laguna afirmando que havia sido descoberto carvão mineral em grande quantidade na localidade de Lajeado do Cedro ${ }^{5}$. Dois anos após, o governo provincial reforçou o feito da descoberta sugerindo que fosse construída uma estrada de ferro ligando as minas aos lugares de embarque do carvão. Para tanto, deveria ser organizada legalmente uma companhia para explorar as minas ${ }^{6}$. Como opção de transportes, foi sugerida a abertura de um canal fluvial em direção ao norte das minas para ligar o Rio Tijucas com a Enseada das Tijuquinhas de São Miguel, onde poderiam transitar pequenos barcos para depois ser baldeado em embarcações maiores rumo à Baía Norte da Ilha de Santa Catarina para o embarque final ${ }^{7}$.

Num relato de 1854, o presidente da Provincia de Santa Catarina, após fazer um panorama sobre as várias expedições nas minas de carvão desde 1832 e com base nos estudos do engenheiro Ernest J. C. Vallée, que tinha sido

\footnotetext{
${ }^{4}$ BRASIL. Relatório do Ministério dos Negócios, da Agricultura, Comércio e Obras Públicas apresentado à Assembléia Geral Legislativa pelo ministro Jesuíno Marcondes de Oliveira e Sá. Rio de Janeiro: Tipografia Universal de Laemmert, 1865. Disponivel em: <http://wwwcrl.uchicago.edu>. Acesso em: 30 maio 2005.

${ }^{5}$ SANTA CATARINA. Fala do presidente da Província de Santa Catarina José Joaquim Machado de Oliveira na abertura da Legislatura Provincial em março de 1837. Cidade do Desterro: Tipografia Provincial, 1837. Disponivel em: $<\underline{\mathrm{http}}: / /$ wwwcrl.uchicago.edu> Acesso em: 30 maio 2005

${ }^{6}$ SANTA CATARINA. Discurso pronunciado pelo presidente da Província de Santa Catarina Brigadeiro João Carlos Pardal na abertura da Assembléia Legislativa em 1839. Cidade do Desterro: Tipografia Provincial, 1839. Disponivel em: $<$ http://wwwcrl.uchicago.edu $>$ Acesso em: 30 maio 2005.

${ }^{7}$ SANTA CATARINA. Fala do presidente da Província de Santa Catarina Brigadeiro Antero José Ferreira de Britto na Assembléia Legislativa em $1^{\circ}$ de março de 1841. Cidade do Desterro: Tipografia Provincial, 1841. Disponivel em: <http:// wwwcrl.uchicago.edu $>$. Acesso em: 30 maio 2005.
}

236 Revista de História Regional 15(2): 235-262, Inverno, 2010 
contratado pelo governo provincial, fez a seguinte observação sobre as dificuldades de transportes:

Desde o princípio se calculou rica a mina do Tubarão, só se tem achado dificuldade na distância do porto de embarque, e não oferecer a barra da Laguna entrada a embarcações de grande lotação .

Os estudos realizados comprovavam a boa qualidade do carvão, porém apontavam dificuldades para o transporte até o porto de embarque. O secular porto de Laguna era, talvez, a única alternativa mais próxima, porém, o problema na entrada da barra inviabilizava a passagem de navios de grande calado que inicialmente deveriam trazer os pesados materiais para a construção da ferrovia e, em seguida, exportar o carvão.

Em 1860, o Visconde de Barbacena contratou James Johnson, profissional de mineração, para fazer um amplo estudo sobre as minas do Tubarão. Os estudos seguiram até o ano de 1862, e, nesse intervalo, o governo imperial concedeu a Barbacena, por meio do Decreto 2.737, de 6 de fevereiro de 1861, o direito de lavrar as minas de carvão de pedra nas margens do Passa Dois, distrito de Laguna. O projeto inicial teve uma alteração em 1864 e foi prorrogado por doze vezes até o ano de 1880. As condições do decreto de 1861 previam o seguinte:

$3^{\text {a }}$ Se for necessário fazer uma estrada de ferro para o transporte do carvão, poderá o Visconde de Barbacena desapropriar o terreno preciso para o leito da mesma estrada e depósitos; não podendo dentro de uma zona de cinco léguas para cada lado, construir-se outra estrada de ferro que siga direção paralela.

$5^{\mathrm{a}} \mathrm{O}$ governo permitirá, durante o tempo que trabalharem as minas, que navios estrangeiros transportem carvão da Laguna para os portos do Império.

$7^{\text {a }}$ O Visconde de Barbacena organizará dentro de dois anos, contados da data da assinatura deste contrato, uma compa-

${ }^{8}$ BRASIL. Relatório do Ministério dos Negócios, da Agricultura, Comércio e Obras Públicas apresentado à Assembléia Geral Legislativa pelo ministro Jesuíno Marcondes de Oliveira e Sá. Rio de Janeiro: Tipografia Universal de Laemmert, 1865, p. 6. Disponivel em: <http://wwwcrl.uchicago.edu>. Acesso em: 30 maio 2005. 
nhia nacional ou estrangeira, que se encarregue do trabalho das minas 9 .

A previsão inicial era fazer uma ligação ferroviária da cabeceira do Rio Tubarão, região das minas, até o porto de Laguna, mas as dificuldades apresentadas na entrada da barra levaram Barbacena a buscar uma nova alternativa. A Enseada de Imbituba, onde havia a armação baleeira, tinha um bom ancoradouro natural, mas também tinha o problema do regime dos ventos norte e nordeste, que dificultariam a atracação dos navios. A única solução viável seria a construção de um quebra-mar. Essa indecisão na escolha do melhor porto para escoar o carvão catarinense deu início a uma longa disputa entre os portos de Laguna e Imbituba para serem escolhidos como porto carvoeiro. É bom lembrar que nesta época a Enseada de Imbituba ficava no municipio de Laguna, somente a 28 quilômetros mais ao norte. O governo imperial optava pelo porto de Laguna, já Barbacena optava pelo porto de Imbituba. Com a vinda dos ingleses, foi reforçada a opção por Imbituba. No Relatório do Presidente da Província de 1870 , temos a seguinte passagem sobre a opção de Barbacena pelo porto de Imbituba:

Consta-me que ele [Barbacena] tivera a idéia de construir uma via férrea entre a mina e a Enseada de Imbituba com o fim de facilitar a condução do material e exportação do carvão, mas é preciso não ter completo conhecimento da Enseada para não aquilatar de sua dificuldade, pois apenas ela dá abrigo aos ventos sudoestes acrescendo que as águas aí têm uma correnteza tal, que é necessário estar o navio sobre 4 espias, além dos ferros, nem tampouco ver que as estradas de ferro que se destinam a condução de uma única mercadoria só poderiam sustentar-se em paises extremamente adiantados ${ }^{10}$.

\footnotetext{
${ }^{9}$ BRASIL. Decreto ${ }^{\circ} 2.737$ de 6 de fevereiro de 1861 . Coleção de Leis do Império do Brasil de 1861. Rio de Janeiro: Tipografia Nacional, tomo XXIV, parte II, 1861, pp. 90-91. Disponivel em: <http://www.camara.gov.br>. Acesso em: 30 maio 2005.

${ }^{10}$ SANTA CATARINA. Relatório apresentado pelo $2^{\circ}$ vice-presidente da Província Manuel do Nascimento da Fonseca Galvão ao presidente André Cordeiro de Araújo Lima em janeiro de 1870. Cidade do Desterro: Tipografia de J. J. Lopes, 1870, p. 18. Disponivel em: <http://wwwcrl.uchicago.edu >. Acesso em: 30 maio 2005. 
O porto Imbituba na formação do complexo carbonífero catarinense.

O Decreto 5.774, de 21 de outubro de 1874, contemporizou os desacordos e concedeu a Barbacena o direito de construir uma estrada de ferro, que deveria partir da cabeceira do Rio Tubarão até a localidade do Passo do Gado, de onde o carvão seguiria via navegação pelo Rio Tubarão até o porto de Laguna. Além disso, o Decreto reconhecia que a ferrovia poderia ser prolongada até Laguna e poderia ser construído um ramal para o porto de Imbituba, ou em outro local do litoral catarinense que melhores vantagens oferecessem ${ }^{11}$. No projeto final, ficou definido que a ferrovia ligaria a região das minas, na cabeceira do Rio Tubarão, até o porto de Imbituba, com um ramal até o porto de Laguna. Finalmente, no dia 18 de dezembro de 1880, partindo da Enseada de Imbituba, foram iniciadas as obras da construção da EFDTC (Estrada de Ferro Dona Tereza Cristina).

\section{Um porto abandonado}

Um ano após o início das obras, o engenheiro fiscal da EFDTC João Carlos Greenhalgh apresentou um relatório apontando os graves problemas do porto de Laguna e do porto de Imbituba. Contudo, Greenhalgh apontava o porto de Imbituba como a melhor solução para o transporte do carvão, onde deveria apenas ser construído um quebra-mar para proteger os barcos dos fortes ventos. Em apenas 12 meses de obras na estrada de ferro, quatro navios transportando materiais para a construção da ferrovia naufragaram na enseada de Imbituba devido à falta de abrigo ${ }^{12}$.

${ }^{11}$ BRASIL. Decreto $\mathrm{n}^{\circ} 5.774$ de 21 de outubro de 1874 . Coleção de Leis do Império do Brasil de 1874. Rio de Janeiro: Tipografia Nacional, 1875, tomo XXXVII, parte II, 1875. Disponivel em: <http://www.camara.gov.br>. Acesso em: 30 maio 2005.

${ }^{1}$ GREENHALGH, João Carlos. Relatório da Ferrovia Dona Tereza Cristina. In: BRASIL. Relatório apresentado à Assembléia Geral na Segunda Seção da Décima Oitava Legislatura pelo ministro dos Negócios da Agricultura, Comércio e Obras Públicas Manuel Alves de Araújo. Rio de Janeiro: Tipografia Nacional, 1882. (anexo ao relatório). 
As obras mais importantes e de maior dificuldade da ferrovia foram as seguintes: a) a ponte das Laranjeiras na Cabeçuda com 1.410 metros de extensão; b) a ponte sobre o Rio Tubarão com 24 metros de extensão; e c) o trapiche em Imbituba. A construção da ponte das Laranjeiras seguia "vagarosamente em razão de grandes dificuldades de introduzir material pela barra da Laguna"13.

Paralelo à construção do trapiche de ferro em Imbituba, em 1882, a Repartição Hidrográfica do Ministério da Marinha, por meio do capitão-tenente Francisco Calheiros da Graça, em função das incessantes reclamações dos comerciantes locais, que temiam prejuízos com a construção do porto de Imbituba, realizou um estudo para projetar as obras de melhoramento na barra e no porto de Laguna ${ }^{14}$.

Enquanto estava sendo construída a ferrovia, no ano de 1883, foi fundada na cidade de Londres, na Inglaterra, a The Tubarão (Brazilian) Coal Mining Company Limited, que ficaria encarregada de explorar as reservas de carvão em Santa Catarina. A EFDTC foi inaugurada dia 01 de setembro de 1884 entre a região das minas (atual município de Lauro Müller) aos portos de Laguna e Imbituba. Estavam constituídos os três pilares iniciais do complexo carbonifero catarinense: mina-ferrovia-porto. A presença dos ingleses na região foi muito efêmera, pois já em 1887 eles simplesmente abandonaram a mina pelo fato de o carvão catarinense ser de baixa qualidade, apresentando um alto teor de rejeito piritoso. Sendo assim, a ferrovia perdia a sua razão de ser, uma vez que ela tinha sido construída apenas para transportar o carvão aos dois portos.

Diante desta situação de abandono, em 1890, o Ministério da Agricultura, Comércio e Obras Públicas elaborou um

\footnotetext{
${ }^{13}$ MINISTÉRIO DA AGRICULTURA, COMÉRCIO E OBRAS PÚBLICAS. Estado de Santa Catarina Relatório apresentado ao ministro Francisco Glicério pelos engenheiros Fabio Hostilo de Moraes Rego, Luiz Filippe Gonzaga de Campos e João Caldeira de Alvarenga Messeder. Rio de Janeiro: Imprensa Nacional, 1890, p. 30 .

${ }^{14}$ CALHEIROS DA GRAÇA, Francisco. Estudos sobre a barra da Laguna. Rio de Janeiro: Tipografia de G. Leuzinger \& Filhos, 1882. 
O porto Imbituba na formação do complexo carbonífero catarinense.

extenso relatório analisando as condições dos portos de Imbituba e Laguna, da estrada de ferro e das minas de carvão. Com relação aos portos, foram apresentadas as seguintes recomendações:

- que seja abandonada, por inoportuna e prejudicial ao inte resse público, toda e qualquer tentativa, por parte do Esta do, de melhoramento da enseada de Imbituba;

- que seja realizado melhoramento do porto e barra de La guna de acordo com o projeto apresentado, pelo meio que o governo julgar mais acertado;

- intervir para que a estrada de ferro reduza de $50 \%$ o atual frete do carvão que, em vez de ir a Imbituba, passará a ser descarregado no porto de Laguna, economizando o percurso de 22 quilômetros ${ }^{15}$.

Segundo as recomendações do Relatório, o porto de Imbituba deveria ser abandonado, pois a sua construção (trapiche de ferro e madeira) foi uma insistência dos ingleses, e o porto de Laguna deveria receber os melhoramentos necessários. Como iniciativa para realizar os melhoramentos no porto de Laguna, em 1892, foi concedido o privilégio para a Companhia de Construção Hidráulica realizar as obras na entrada da barra e no porto de Laguna ${ }^{16}$.

Com o abandono da área carbonífera pelos ingleses, Barbacena, em 1886, transferiu a concessão dos terrenos carboníferos à firma carioca Lage \& Irmãos. Já a EFDTC, dada a situação de abandono, em 1902 o governo brasileiro encampou-a. Com o fim da presença inglesa, o governo retomou um antigo projeto da construção de um porto na Enseada de Massiambu, próxima ao sul da Ilha de Santa Catarina, onde não havia problema de assoreamento e de ventos. Em 1906, foi baixado o Decreto 5.977, de 18 de abril, que aprovou as cláusulas do contrato para o futuro arrendamento da EFDTC e para a construção das obras do porto de

${ }_{15}$ MINISTÉRIO DA AGRICULTURA, COMÉRCIO E OBRAS PÚBLICAS. Op. cit. p. 75 .

${ }^{16}$ BRASIL. Decreto $n^{\circ} 1.034$ de 14 de novembro de 1890. Disponivel em $<\underline{\mathrm{http}: / /}$ www.senado.gov.br>. Acesso em: 11 de abril 2005. 
Massiambu. As mudanças previstas para a ferrovia e o porto de Imbituba eram as seguintes:

a) suprimir o trecho do porto de Imbituba até o entroncamento com o ramal da Laguna;

b) transferir as oficinas existentes naquele porto para onde melhor convier;

c) aproveitar os materiais do trecho suprimido para o estabelecimento de ramais que se dirijam para as minas de carvão ${ }^{17}$.

Em cumprimento ao referido decreto, em 1906, a oficina da ferrovia, que ficava em Imbituba, foi transferida para Tubarão.

Até 1917, o porto recebia apenas os navios da Companhia Nacional de Navegação Costeira, da firma Lage \& Irmãos, que escoava mercadorias em geral (cereais, madeira e banha) e uma pequena quantia de carvão que era explorada de forma quase artesanal ${ }^{18}$. Nesse mesmo ano, o Congresso Nacional negou a Henrique Lage, proprietário da Lage \& Irmão o pedido para a construção, uso e gozo do porto de Imbituba $^{19}$. Afinal, nesse momento estavam sendo executadas as obras de melhoramento do porto de Laguna e se cogitava ampliar o ramal ferroviário até Massiambu. Porém, em 1919, Henrique Lage obteve a concessão do Ministério de Viação e Obras. Com a autorização expedida pelo governo, a Lage \& Irmãos iniciou as obras de melhoramento do porto, que compreendiam a construção de um quebra-mar, armazéns, oficinas e compras de matérias flutuantes.

No relatório sobre os trabalhos executados no porto de Laguna no ano de 1922, o engenheiro Candido Lucas Gaffré fez uma minuciosa descrição sobre a clandestinidade com que estavam sendo conduzidas as obras em Imbituba, em detrimento dos interesses da comunidade de Laguna.

\footnotetext{
${ }^{17}$ BRASIL. Decreto $n^{\circ} 5.977$ de 18 de abril de 1906. Disponivel em: $<$ http://www. senado.gov.br>. Acesso em: 11 de abril 2005.

${ }^{18}$ MINISTÉRIO DA VIAÇÃO E OBRAS PÚBLICAS. Relatório da Inspetoria Federal de Portos, Rios e Canais dos servicos prestados em 1920 apresentado ao ministro pelo Inspetor Federal Lucas Bicalho. Rio de Janeiro: Imprensa Nacional, 1922.

${ }^{19}$ BOSSLE, Ondina Pereira. Henrique Lage e o desenvolvimento sul catarinense. Florianópolis: Editora da UFSC, 1981. 
O porto Imbituba na formação do complexo carbonífero catarinense.

É meu dever levar ao conhecimento de V.EX. alguns fatos a respeito deste porto que, pode-se dizer, está sendo construído clandestinamente. Nele, essa Inspetoria não tem a mínima fiscalização. [...] Este porto está prejudicando seriamente o comércio desta cidade ${ }^{20}$.

Gaffré se colocou ao lado da comunidade lagunense, já que era o engenheiro-chefe das obras do porto de Laguna, e recomendou à Inspetoria que as obras em Imbituba fossem paralisadas, a não ser que fossem aprovados o projeto e orçamento pelo Ministério. As críticas de Gaffré eram dirigidas principalmente à firma Lage \& Irmãos que estava realizando as obras no porto de Imbituba, que, segundo Gaffré, tinha licença ilegal.

Na segunda edição da obra de Alfredo Lisboa, intitulada Portos do Brasil, em 1928, foi acrescida uma pequena descrição sobre o porto de Imbituba, que não havia na primeira edição de 1922. Segundo Lisboa, depois de concluídas as obras no porto de Laguna, o porto de Imbituba não poderia concorrer com o de Laguna, pois as mercadorias deveriam percorrer mais um trecho ferroviário de 15 quilômetros ${ }^{21}$.

Com os adventos da Primeira Guerra Mundial e o cerceamento do fluxo internacional de mercadorias, a importação de carvão sofreu uma queda, forçando o governo brasileiro a buscar alternativas internas como fontes energéticas. Foi neste momento que a região sul de Santa Catarina assistiu a uma rápida expansão das atividades carboniferas. Durante os anos da guerra foram constituídas duas companhias carboníferas em Santa Catarina: a CBCA (Companhia Brasileira Carbonífera Araranguá S.A), e a CCU (Companhia Carbonífera Urussanga S.A.). Nos anos de 1920 foram fundadas a Companhia Carbonífera Próspera S.A, a Companhia Carbonífera Ítalo Brasileira Ltda., e a Companhia Nacional Mineração Barro Branco. Durante a Primeira Guerra Mundial, a firma Lage \& Irmãos começou a investir na exploração do carvão em Santa Catarina abrindo minas

${ }^{20}$ GAFFRÉ, Candido Lucas. Relatório dos trabalhos da comissão de obras do porto de Laguna. Inspetoria Federal de Portos, Rios e Canais, 1923, pp. 11-12.

${ }^{21}$ LISBOA, Alfredo. Portos do Brasil. 2. ed., Rio de Janeiro: O Norte, 1928. 
e aparelhando o porto de Imbituba. O desenvolvimento das atividades carboníferas refletiu em vários outros aspectos da vida nesse espaço sócio-ambiental que ficou conhecido como a Região Carbonífera ${ }^{22}$.

\section{A fundação da Companhia Docas de Imbituba}

Com a ampliação das atividades carboníferas em Santa Catarina e a persistência do problema do porto de Laguna, mesmo com todo o investimento feito pelo governo federal, a Lage \& Irmãos resolveu ampliar o porto de Imbituba. No dia 3 de novembro de 1922, foi fundada a CDI (Companhia Docas de Imbituba), que nasceu assumindo toda a área portuária (principalmente o quebra-mar em construção) e as instalações existentes (oito armazéns, ferrarias, oficinas, máquinas, acessórios e materiais flutuantes). Segundo o seu estatuto, a Companhia deveria continuar a construção do quebra-mar e executar obras e aparelhamentos necessários ao porto ${ }^{23}$. Depois da fundação da Companhia Docas, a Navegação Costeira, que fazia paradas esporádicas em Imbituba, "tornouse assídua na exportação de carvão e outras mercadorias"24. Segundo o engenheiro Lucas Bicalho, que fez um estudo do porto de Imbituba, em 1925:

Há ali uma linha regular de navegação para carga e passageiros, com um navio em cada 10 dias nos dois sentidos de sul e norte, realizado pela Companhia Nacional de Navegação Costeira, que o faz com os seus navios mais antigos, prestando mesmo assim relevante serviço à região servida pela Estrada de Ferro Dona Teresa Cristina que parte desse porto para Laguna, Tubarão, Lauro Müller, Araranguá e Urussanga ${ }^{25}$.

\footnotetext{
${ }^{22}$ GOULARTI FILHO, Alcides. Formação econômica de Santa Catarina. Florianópolis: Cidade Futura, 2002

${ }^{23}$ COMPANHIA DOCAS DE IMBITUBA. Ata de fundação da Companhia Docas de Imbituba. Rio de Janeiro, 3 de novembro de 1922

${ }^{24}$ BOSSLE, Ondina. Op. cit., 42.

${ }^{25}$ BICALHO, Lucas. Comissão de Estudos e Obras dos Portos de Laguna e Imbituba: Porto de Laguna. In MINISTÉRIO DA VIAÇÃO E OBRAS PÚBLICAS. Relatório da Inspetoria Federal de Portos, Rios e Canais dos serviços prestado no ano de 1924 apresentado ao Ministro pelo Inspetor Federal Hidelbrando de Araújo Góes. 
Entre 1922 e 1935, as obras do porto de Imbituba seguiram um ritmo muito lento, pois dependiam exclusivamente dos recursos oriundos da Lage \& Irmãos. Num discurso pronunciado na Câmara dos Deputados, no dia 25 de outubro de 1937, o então deputado Henrique Lage fez uma longa explanação comparando os portos de Laguna, Massiambu e Imbituba. Defendendo seus interesses, Lage alegava que Imbituba era o porto que melhores condições apresentava para o transporte do carvão. As obras estavam seguindo um ritmo muito lento, pois, segundo Lage, eram executadas apenas com recursos próprios. Segue um pequeno trecho do seu pronunciamento:

A impropriedade de Laguna e Massiambu para a instalação de estações carvoeiras em grandes proporções, coloca Imbituba como solução pela exportação econômica do carvão de Santa Catarina. As instalações que Imbituba precisam ainda:

a) guindaste tipo "Titan" para colocação de blocos de pedra de 50 toneladas cada um no quebra-mar já iniciado;

b) aumento do cais para 400 metros corridos;

c) caixa de embarque para navios de mais de 6.000 toneladas.

Esse aparelhamento permitirá o barateamento do carvão, pela diminuição dos fretes marítimos. Tudo indica a necessidade de um auxilio financeiro por parte do Governo para ser executada com urgência essa obra portuária ${ }^{26}$.

Em dezembro de 1935, foram iniciadas as obras do cais acostável de 100 metros, do silo para depósito de carvão com capacidade para 3.000 toneladas, do caixão de fundação, da moega subterrânea com capacidade para 20 toneladas e das correias (alimentadora, elevadora e distribuidora). As obras foram executadas pela Companhia Nacional de Construções Civis e Hidráulicas, da Organização Henrique Lage ${ }^{27}$.

Rio de Janeiro: Imprensa Nacional, 1926, p. 181

${ }^{26}$ LAGE, Henrique. Diário do Poder Legislativo. Rio de Janeiro: Câmara dos Deputados, ano IV, n. 750, 24 de outubro de 1937.

${ }^{27}$ COMPANHIA DOCAS DE IMBITUBA. Porto Henrique Lage. Imbituba, 9/ março/ 1946. 
Por ser um mineral básico para a industrialização, em 1931, o governo Vargas decretou a obrigatoriedade do consumo de 10,0\% de carvão nacional. Em 1937, a cota foi elevada para $20,0 \%$, e, em 1942, dentro do "esforço de guerra", foi encampada toda a produção, elevando-a de 204.181 toneladas, em 1939, para 815.678 toneladas, em 1945. Além das medidas institucionais, foram feitos investimentos estatais diretos, como a construção do novo porto de Laguna e a construção pela CSN (Companhia Siderúrgica Nacional de Volta Redonda) de um de lavador de carvão (usina de beneficiamento do carvão), em Tubarão. Com a entrada em operação do lavador da CSN, em 1946, foi incorporada uma importante unidade dentro do complexo carbonífero catarinense. Paralelo à rápida expansão das atividades carboníferas, as obras no porto de Imbituba continuavam num ritmo mais lento. A concessão do direito de explorar o porto de Imbituba foi autorizada à CDI somente em 1941, com o Decreto 7.842, de 13 de setembro.

No final dos anos 1930, as Organizações Henrique Lage estavam passando por dificuldades financeiras com dividas crescentes e essa situação se agravou com a morte de Henrique Lage, em julho de 1941. Diante desta situação falimentar o Decreto-Lei 4.648, de 2 de setembro de 1942, incorporou ao patrimônio nacional todos os bens e direitos da Organização Lage e do espólio de Henrique Lage, uma vez que a única herdeira de Lage era sua esposa Gabriela Bezanzoni, que era italiana. Como o Brasil havia declarado guerra ao Eixo e a Organização Henrique Lage estava quase insolvente, Vargas resolveu encampá-la. Pouco antes de ser encampada, em março de 1942, foram inauguradas as obras do porto, que estava sob responsabilidade de Francisco João Bocayuva Catão.

Após apelos dirigidos ao presidente Eurico Gaspar Dutra, pela família Catão, em 26 de julho de 1946, foi editado o Decreto 9.521, que regulou o destino dos bens deixados por Henrique Lage. Uma parte expressiva do patrimônio continuou sob responsabilidade da União, outra parte, incluindo as minas de carvão e o porto de Imbituba, foram entregues 
à viúva de Henrique Lage. Em 1950, Gabriela reuniu-se com Francisco João Bocayuva Catão, administrador do porto, e repassou a ele suas propriedades em Santa Catarina, que incluíam a Companhia Docas de Imbituba e as companhias carboníferas CBCA e Barro Branco ${ }^{28}$.

\section{A consolidação do porto carvoeiro}

Durante a Segunda Guerra Mundial, estavam sendo construídos concomitantemente os portos de Laguna e Imbituba. Laguna já era um porto público, o de Imbituba tinha sido encampado em setembro de 1942, portanto, durante a Guerra; ambos dependiam de recursos públicos. O problema de Imbituba, a falta de abrigo, foi solucionado com a construção do quebra-mar, já o de Laguna, o assoreamento na entrada da barra, ainda persistia. Com o fim da Guerra, e diante da irreversibilidade do problema de Laguna, o governo optou pelo porto de Imbituba e o transformou no único porto carvoeiro de embarque no país. Após o fim da Guerra houve uma queda considerável no consumo do carvão energético, concomitante, começou a ser consumido pela recém-inaugurada CSN (Companhia Siderúrgica Nacional) o carvão metalúrgico. O carvão extraído nas minas de Criciúma, Urussanga, Lauro Müller e Siderópolis era transportado pela Estrada de Ferro Dona Teresa Cristina até o lavador de carvão da CSN, localizado em Tubarão, onde era separada a fração metalúrgica do rejeito. Do lavador, o carvão metalúrgico seguia por trem até o porto de Imbituba de onde era escoado para as siderúrgicas estatais no Sudeste.

Apesar de uma queda na produção no imediato pósguerra, as atividades carboniferas continuaram se expandindo durante os anos de 1940 e 1950. Em 1947, foram aprovadas para o porto de Imbituba as obras de ampliação no porto pelo Decreto 22.650, de 27 de fevereiro, que também apro-

${ }^{28}$ CATÃO, Francisco João Bocayuva. Carta aos imbitubenses. Imbituba, 28 de janeiro de 1997. 
vou o orçamento cujas obras tinham por objetivo aumentar a capacidade de estocagem do carvão. Para facilitar e agilizar o carregamento e liberar o mais rápido possivel os vagões da ferrovia, o cais foi ampliado em mais 40 metros, totalizando 140 metros $^{29}$.

A segunda ampliação de cais foi iniciada somente em 1968, financiada pelo DNPVN (Departamento Nacional de Portos e Vias Navegáveis) e executada pela Construtora SULTEPA do Rio Grande do Sul, com a construção do cais $n^{\circ} 2$ de 168 metros, elevando ao todo para 308 metros $^{30}$. Em seguida, entre 1972 e 1975, foi ampliado o molhe de abrigo a partir de um estudo realizado pelo Laboratório Central de Hidráulica da França em 1946 e executado pela BH Engenharia e pela Construtora Sultepa ${ }^{31}$. Nos estudos do laboratório francês, estava prevista a construção de dois molhes: molhe norte, enraizado no morro das Ovelhas, e molhe sul. O projeto do molhe norte nunca foi executado.

Esta ampliação foi executada com o objetivo de aumentar a capacidade de movimentação de carvão, em razão do aumento do consumo do carvão metalúrgico pelas siderurgias estatais. Em 1969, foi fundada a ICC (Indústria Carboquímica Catarinense), uma empresa pertencente ao Grupo Petrofértil, cujos objetivos eram produzir insumos para indústria de fertilizantes a partir do enxofre extraído da pirita carbonosa (rejeito do carvão) derivando o ácido sulfúrico somado ao ácido fosfórico. A construção da ICC, inaugurada em 1979, fazia parte dos objetivos do II PND (Plano Nacional de Desenvolvimento). Para descarregar a rocha fosfática, matériaprima para a produção do ácido fosfórico, e para escoar toda a produção de ácido sulfúrico e fosfórico, necessariamente o porto de Imbituba deveria ampliar suas instalações ${ }^{32}$. Além

\footnotetext{
${ }^{29}$ PORTO HENRIQUE LAGE. Memória justificativa das modificações a introduzir no projeto aprovado pelo Decreto 22.650 de 27 de fevereiro de 1947. Rio de Janeiro, 23 de agosto de 1949.

${ }^{30}$ CONSTRUTORA SULTEPA. Contrato firmado entre a Sultepa e a CDI. Porto Alegre, 10 de abril de 1974.

${ }^{31}$ DEPARTAMENTO NACIONAL DE PORTOS E VIAS NAVEGÁVEIS. Molhe de Imbituba - Relatório Final. Porto Alegre, 17/09/1975.

${ }^{32}$ MORAES, Fabio Farias. A Indústria Carboquímica Catarinense (ICC): uma so- 
disso, outro objetivo do II PND era substituir os produtos derivados de petróleo. Para tanto, o carvão catarinense passou a ser prioritário dentro da política nacional energética.

A terceira ampliação de cais, para atender à ICC e ao aumento da demanda por carvão, se iniciou em 1979, financiado pela Portobrás. Esta ampliação estava prevista no Plano Diretor Portuário do Brasil 1975-1984 e também foi incorporada pelo II PND, que reforçou o projeto de prolongamento do molhe e a construção de instalações para o carvão. O cais seria ampliado em mais 245 metros, com largura de 40 metros. Os objetivos da ampliação do porto de Imbituba, segundo o Plano Diretor, eram: atender às exportações de carvão previstas no Plano Siderúrgico Nacional e atender as demandas da ICC. Deve-se destacar a expectativa que foi gerada na região com o Projeto Sidersul (Siderúrgica Sul Catarinense), que seria implantado em Imbituba.

No Plano Diretor Portuário de 1979, estava prevista a ampliação do porto de Imbituba para atender à importação da rocha fosfática, à exportação de concentrado fosfático e à exportação de ácido fosfórico para suprir às demandas da ICC; à importação de minério de ferro para atender à Sidersul; além da carga geral, principalmente o açúcar ensacado e a carga de roll-on. Segundo o Plano, naquele momento "[...] as atuais instalações portuárias atingiram praticamente $o$ limite da sua capacidade e o atual sistema de movimentação de carvão não é adaptável aos novos fluxos" ${ }^{33}$. O rápido crescimento da exportação (cabotagem) do carvão estava estrangulando o porto de Imbituba. Além disso, a entrada em operação da ICC e a possivel construção da Sidersul comprometiam ainda a capacidade do porto. Para tanto, o Plano recomendava que deveriam começar "com a maior brevidade" os planos previstos, uma vez que o porto estava "atingindo o seu limite de capacidade" ${ }^{34}$.

lução ou um problema? In: GOULARTI FILHO, Alcides (Org.). Memória e cultura do carvão em Santa Catarina. Florianópolis: Cidade Futura, 2004.

${ }^{33}$ MINISTÉRIO DOS TRANSPORTES. Plano Diretor Portuário do Brasil: Porto de Imbituba. Brasilia: Portobrás, 1979, p. 91.

${ }^{34}$ MINISTÉRIO DOS TRANSPORTES. Op. cit., p.93. 
Atendendo às novas exigências antes que a ICC entrasse em operação, em 1979, iniciaram a construção do novo cais de 245 metros, sendo concluído em $1983^{35}$. No quadro abaixo, podemos acompanhar a evolução da construção do cais velho, do cais novo e do cais roll-on, que, ao todo, somam 577 metros de cais.

Quadro 1: Evolução da construção dos cais no porto de Imbituba

\begin{tabular}{|c|c|c|c|}
\hline Cais e berços & $\begin{array}{c}\text { Entrada em } \\
\text { operação }\end{array}$ & $\begin{array}{c}\text { Comprimento } \\
(\mathrm{m})\end{array}$ & $\begin{array}{c}\text { Profundidade } \\
(\mathrm{m})\end{array}$ \\
\hline Cais Velho (carvão) & 1942 & 100 & 9,5 \\
Berço 1 & 1959 & 40 & 9,5 \\
Berço 2 & 1970 & 168 & 9,5 \\
\hline $\begin{array}{c}\text { Cais Novo (rocha e ácido fos- } \\
\text { fórico e carga geral) } \\
\text { Berço 3 }\end{array}$ & 1983 & 245 & 9,5 \\
\hline Roll-on & 1981 & 24 & 9,5 \\
\hline
\end{tabular}

Fonte: MINISTÉRIO DOS TRANSPORTES. Estudo específico para análise de movimentação portuária: Porto de Imbituba. Brasília: Geipot, 1994, p. 24-25.

Pelo fato de ser um importante porto para o Plano Siderúrgico Nacional, Imbituba sempre foi contemplada nos planos nacionais. No Plano de Reaparelhamento e Ampliação dos Portos Organizados elaborado, em 1947, para Imbituba, estavam previstos $1,29 \%$ do total dos recursos destinados aos portos brasileiros ${ }^{36}$. No Plano Portuário Nacional 19601962 e no de 1963-1966 para Imbituba, estavam previstos obras e serviços de expansão e melhoramento. Imbituba também foi contemplado no Plano Diretor de 1974 e no de 1979 , porém, não fez parte do Plano de Desenvolvimento Portuário de 1986.

\footnotetext{
${ }^{35}$ PORTOBRÁS. Termo de entrega e recebimento das obras de construção de píer para movimentação de granéis no porto de Imbituba. Imbituba, julho de 1983. 36 MINISTÉRIO DA VIAÇÃO E OBRAS PÚBLICAS. Relatório dos serviços executados pelo Departamento Nacional de Portos, Rios e Canais no ano de 1947 apresentado ao ministro da Viação e Obras Públicas pelo diretor geral Clovis de Macedo Cortes. Rio de Janeiro: Imprensa Nacional, 1950.
} 
O porto Imbituba na formação do complexo carbonífero catarinense.

Ao longo dos anos 1980, o porto movimentou em média 3,29 milhões de toneladas de carga, sendo 2,43 milhões de carvão, ou seja, de toda carga movimentada $73,86 \%$ era carvão, principalmente o metalúrgico. O porto fazia parte do complexo carbonífero catarinense formado por minas, ferrovia, lavador, termoelétrica, carboquímica e porto. Na segunda metade dos anos de 1980, começaram os cortes nos subsídios para o transporte ferroviário do carvão e o aumento das importações do carvão metalúrgico. Com isto, a movimentação no porto começou a cair rapidamente. Em 1990, o governo Collor liberou por completo a importação do carvão metalúrgico e fechou o Lavador de Capivari e as minas da CSN. A exportação de carvão por Imbituba passou de 2,0 milhões de toneladas em 1988 para 795 mil em 1990, zerando em 1994. Imbituba deixava de ser o porto carvoeiro e necessitava urgentemente de uma reestruturação. Para agravar ainda mais a situação do porto, a ICC foi reduzindo a produção a partir de 1992, e, em 1994, encerrou suas atividades.

Crise e tentativas de reestruturação

O desmonte parcial do complexo carbonífero catarinense, com o fim do transporte de cabotagem do carvão metalúrgio e a desativação da ICC, geraram alta capacidade ociosa no porto no início dos anos de 1990. A situação crítica da CDI foi temporariamente resolvida com a reestruturação do porto para o transporte de contêineres, mas logo as expectativas frustraram-se devido a problemas na gestão e na relação com os usuários. Nessa fase de reestruturação, o silo de carvão foi desmontado, e foi construído o TERFRIO (Terminal Frigorífico) pelos Armazéns Gerais de Imbituba ${ }^{37}$. Mesmo com a Lei de Modernização dos Portos, de 1993, a CDI

${ }^{37}$ COMPANHIA DOCAS DE IMBITUBA. ADPORT n ${ }^{\circ}$ 839/95. Imbituba, dezembro de 1995. 
atuava como administradora e operadora portuária que, nos anos de auge do complexo carbonífero, fazia uma diferença e era positivo para a Companhia. Porém, anos mais tarde, tornou-se um sério entrave para as operações portuárias.

Depois do final das exportações do carvão e do fechamento da ICC, parecia que a situação econômica do porto começaria a se reverter para a CDI. Porém, uma mudança arbitrária nas tarifas portuárias promovida pela CDI, em 1995, que as elevou em 100\%, causou uma evasão de cargas conteinerizadas, reduzindo a zero! Novamente, o porto entrou numa crise. Após uma mudança gerencial, os novos gestores reiniciaram a corrida em busca pelo tempo perdido, uma vez que São Francisco do Sul, Itajaí e Rio Grande canalizaram todas as linhas e clientes (exportadores e importadores). A atividade de operação foi separada da administração, ficando a CDI apenas com a segunda. Dentro da recente reestruturação, também foi arrendada parte da área portuária e dos armazéns para outras empresas, como a Cimport (Grupo Votorantin), a Fertisanta e a Via Expressa ${ }^{38}$.

A cidade de Imbituba sempre esteve pautada no porto e na expectativa de grandes investimentos externos. Primeiro, foi a tentativa da construção da Sidesc, que se transformou em ICC e gerou um caos ambiental na cidade. A ICC encerrou suas atividades e deixou um grande passivo ambiental de mais de 4,3 milhões de toneladas de gesso e 1,4 milhões de toneladas de óxido de ferro. A segunda foi o Projeto Sidersul, que consumiu mais de 24 milhões de dólares do governo estadual, e nada foi realizado. A última redenção de Imbituba foi a ZPE, a promessa de atrair indústrias e integrá-las com o porto. Na reforma administrativa de 2005 do governo estadual, a ZPE foi extinta ${ }^{39}$.

Para o porto de Imbituba, a melhor solução seria servir de porto regulador e complementar de Itajaí e São Francisco do Sul. Ou seja, na impossibilidade de os navios atracarem

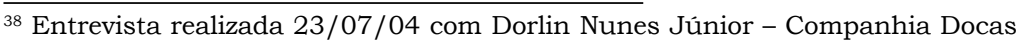
de Imbituba.

${ }^{39}$ GOULARTI FILHO, Alcides (Org.). Memória e cultura do carvão em Santa Catarina. Florianópolis: Cidade Futura, 2004. 
O porto Imbituba na formação do complexo carbonífero catarinense.

em Itajaí e São Francisco do Sul, o porto de Imbituba deveria oferecer condições para estes navios. Esta é a mesma condição que estava colocada para o porto de São Francisco do Sul e Itajaí no início dos anos 1970. O porto de São Francisco do Sul ficou fora do programa de Corredores de Exportação e deveria apenas ser um regulador de Paranaguá nas exportações de grãos. O de Itajaí deveria ser um regulador do porto de Santos na movimentação de contêineres. Enquanto isto, Laguna seguia a sua trajetória letárgica, e, em 1969, começava outra batalha hercúlea para construir o porto pesqueiro. Nesse momento, o porto de Imbituba era o único que apresentava boas perspectivas, pois estava passando por uma ampliação (conclusão do berço 2 e planejando a construção do cais 2), e apostando nos futuros investimentos da ICC e da Sidersul. Apenas o porto de Imbituba foi incluído no II PND dentro do Projeto Litoral Sul da Sudesul (Superintendência de Desenvolvimento do Sul) e dos planos da Portobrás.

No entanto, nos anos 1990, a situação econômica e o movimento de carga se inverteram para a CDI. Os maiores problemas para os portos de São Francisco do Sul e Itajaí foram maiores vantagens para o porto de Imbituba. Imbituba tem uma grande retroárea, fácil acesso rodoviário e marítimo (enseada em mar aberto) e não está encravado no meio da cidade. São justamente nestes quesitos que São Francisco do Sul e Itajaí perdem para Imbituba, porém ambos têm uma maior agilidade na movimentação de cargas e uma adminstração mais estável. Com relação à administração, foi, segundo os atuais gestores, justamente pelas mudanças brusca nos rumos da gestão da CDI, em 1995, que o porto perdeu todos os clientes que movimentavam contêineres ${ }^{40}$.

${ }^{40}$ Entrevista realizada 23/07/04 com Dorlin Nunes Júnior - Companhia Docas de Imbituba 
Quadro 2 :Evolução da movimentação de contêineres nos três por tos catarinenses 1990-2000

\begin{tabular}{c|c|c|c}
\hline Ano & São Francisco do Sul & Itajaí & Imbituba \\
\hline 1990 & 280.967 & 190.514 & 7.956 \\
\hline 1991 & 334.780 & 254.081 & 34.977 \\
\hline 1992 & 340.947 & 431.339 & 162.617 \\
\hline 1993 & 452.319 & 597.018 & 309.638 \\
\hline 1994 & 730.481 & 633.885 & 413.912 \\
\hline 1995 & 971.564 & 643.796 & 663.527 \\
\hline 1996 & 982.249 & 840.657 & 25.019 \\
\hline 1997 & 1.197 .083 & 1.160 .457 & 81.415 \\
\hline 1998 & 1.443 .675 & 1.266 .296 & 6.583 \\
\hline 1999 & 1.625 .039 & 1.316 .765 & 16.543 \\
\hline 2000 & 1.547 .694 & 1.698 .352 & - \\
\hline
\end{tabular}

Fonte: Ministério dos Transportes. Disponivel em: <http://www. transporte.gov.br>. Acesso em: 20 maio 2006.

\section{Porto, ferrovia e movimento de cargas}

O porto de Imbituba foi construído pelos ingleses para receber o material necessário para a construção da Estrada de Ferro Dona Teresa Cristina, que se tornou o mais importante meio de acesso ao porto até 1990. No início do século, pela ferrovia eram transportados carvão, cereais, madeira, banha e carne. No final dos anos 1960, foi abandonado o transporte de pessoas e mercadorias em geral, concentrando-se apenas no carvão.

O porto de Imbituba transportou durante um século grande parte do carvão nacional consumido nos transportes (ferroviário e navegação-fluvial e marítima) e nas siderurgias (carvão metalúrgico). Com o fim da movimentação do carvão no porto de Laguna, a partir de 1945, Imbituba assumiu a liderança exclusiva do transporte do carvão catarinense. Na segunda metade dos anos 1970, em função das estratégias do II PND, o consumo do carvão catarinense aumentou de forma exponencial. Em 1975, foram transportados pelo 
porto 829 mil toneladas de carvão; em 1980, já eram 2,18 milhões, chegando a 2,66 milhões de toneladas, em 1985. Com o início do desmonte parcial do complexo carbonífero, o transporte de carvão caiu vertiginosamente, chegando a 795 mil toneladas em 1990, ou seja, o mesmo nivel do final dos anos 1960. A última tonelada de carvão transportada foi em 1993 (Anexo 1).

Com a entrada em operação da ICC e do berço 3, iniciou-se o transporte de rocha fosfática e ácido fosfórico. Os granéis exportados (cabotagem), fora o carvão, passaram de uma média de 11,48 mil toneladas (1,07\% sobre o total), nos anos 1970, para 198,55 mil toneladas nos anos $1980(5,65 \%$ sobre o total). Em compensação, nos anos 1990, passaram para 28,20 mil (2,63\% sobre o total), zerando em 2000 . O cais destinado quase que exclusivamente a ICC foi adaptado para outros tipos de carga.

Com relação à movimentação de contêineres, podemos dividi-la em dois momentos. O primeiro é de 1990 a 1995, quando se iniciou a movimentação, e rapidamente o porto se adaptou à nova realidade. Em 1990, foram movimentadas 7.956 toneladas, bem abaixo de São Francisco do Sul e Itajaí. Em compensação, em 1995, Imbituba movimentou mais toneladas de contêineres do que Itajaí. E no número de contêineres, em 1994, Imbituba liderou, movimentando 59.423 unidades (Anexo 1).

O segundo momento começou em 1996 e se estendeu até 2005, quando as tarifas portuárias foram duplicadas sem aviso prévio para os operadores. O movimento de contêineres começou a cair vertiginosamente, chegando a 16.543 toneladas, em 1999. O porto que estava se reestruturando da crise do carvão quase voltou à estaca zero. Tanto que, em 1996, a movimentação geral de carga foi 384.618 toneladas, um nivel igual a 1945, e, no ano seguinte, 575.658 toneladas, igual a 1951 (Anexo 1).

Além do carvão, Imbituba transportava açúcar e farinha produzidos na hinterland, no sul de Santa Catarina, e também os produzidos nas proximidades de Florianópolis, 
porém estas mercadorias cederam espaço para o carvão e os produtos da ICC, que, nos anos 1980, tornaram-se quase absolutos.

A tendência do porto de Imbituba ao longo do século $\mathrm{XX}$ foi quase sempre se ajustar às demandas externas, e raramente houve grandes esforços internos para dinamizar a sua estrutura, diversificando e ampliando sua carteira de clientes/usuários. Primeiro, ajustou-se ao Plano Nacional do Carvão, depois aos planos da Petrofértil, além de ficar na expectativa dos planos da Siderbrás (Sidesc e Sidersul) e da ZPE. A tentativa de reestruturação dos anos 1990 foi abortada, e, atualmente, a CDI busca inovar arrendando áreas e armazéns da sua ampla retro-área. A recente ampliação de novas linhas, segundo Dorlin Nunes Júnior, traz expectativas positivas para a atual administração do porto, que pretende, no mínimo, resgatar a movimentação de contêineres que teve em 1994 e 1995.

\section{Reflexões finais}

Tomando como referência o ano de 1880, quando foram iniciadas as obras de construção e observado o movimento da longa duração no porto de Imbituba no século XX, é possivel identificar quatro periodos, destacando a evolução estrutural, a movimentação de carga e a administração do porto de Imbituba.

a) 1880 a 1919 - Construção e abandono do porto inglês: concomitantemente a construção da EFDTC, o porto de Imbituba foi sendo construído para escoar a produção de carvão. A falta do quebra mar dificultava a entrada de navios na enseada aberta. Com a saída dos ingleses, em 1902, o porto foi abandonado e cogitou-se construir outro porto em Massiambu. 
b) 1919 a 1942 - Porto Henrique Lage: em 1919, Henrique Lage assumiu o porto e fez dele um ancoradouro para os seus navios. Recomeçaram a movimentação de cargas gerais (alimentos e madeira) e carvão, e as obras de melhoramentos. Em 1922, foi organizada a Companhia Docas de Imbituba, encarregada de concluir as obras. Em 1941, o porto foi encampado pelo governo Vargas.

c) 1942 a 1990 - Porto carvoeiro do Plano Nacional do Carvão: em 1942, sob a tutela do governo, as obras do novo porto foram inauguradas e Imbituba disputou com Laguna o título de exclusividade de "porto carvoeiro". Nesse periodo, o porto de Imbituba se ajustou ao Plano Nacional do Carvão. Em 1979, passou a atender às demandas da ICC.

d) $\mathbf{1 9 9 0}$ à atual - Tentativas de reestruturação: com o fim das exportações do carvão e o fechamento da ICC, houve uma tentativa de reestruturação do porto, adaptando-o para a movimentação de contêineres. $\mathrm{Na}$ segunda metade da década, novamente o porto voltou a operar com alta capacidade ociosa.

O porto de Imbituba, que já foi o porto carvoeiro que se adaptou às exigências do Plano Nacional do Carvão, entrou em crise em 1990 e rapidamente transformou-se num porto de carga geral movimentando cargas conteinerizadas, mas novamente entrou em crise e atualmente busca uma nova especialização para integrar-se à economia catarinense. 
Alcides Goularti Filho

Anexo 1: Navios e cargas movimentadas no porto de Imbituba 1944-2000

\begin{tabular}{|c|c|c|c|c|c|c|c|c|c|}
\hline \multirow{4}{*}{ Ano } & \multirow{2}{*}{\multicolumn{2}{|c|}{ Números de navios }} & \multirow{2}{*}{\multicolumn{4}{|c|}{ Exportação (t) }} & \multicolumn{3}{|c|}{ continua } \\
\hline & & & & & & & Importac & ão (t) & \multirow{3}{*}{ Total } \\
\hline & \multirow{2}{*}{ Cabotagem } & \multirow{2}{*}{$\begin{array}{c}\text { Longo } \\
\text { curso }\end{array}$} & \multicolumn{2}{|c|}{ Carvão } & \multicolumn{2}{|c|}{$\begin{array}{c}\text { Carga geral e } \\
\text { graneleiro }\end{array}$} & \multicolumn{2}{|c|}{$\begin{array}{c}\text { Carga geral e } \\
\text { graneleiro }\end{array}$} & \\
\hline & & & Cabotagem & $\begin{array}{c}\text { Longo } \\
\text { curso }\end{array}$ & Cabotagem & $\begin{array}{c}\text { Longo } \\
\text { curso }\end{array}$ & Cabotagem & $\begin{array}{c}\text { Longo } \\
\text { curso }\end{array}$ & \\
\hline 1918 & 93 & & 2.060 & & & & & & \\
\hline 1919 & 86 & & 4.454 & & & & & & \\
\hline 1920 & 93 & & 14.584 & & & & & & \\
\hline 1921 & 88 & & 8.318 & & & & & & \\
\hline 1922 & 119 & & 28.233 & & & & & & \\
\hline 1923 & 134 & & 35.393 & & & & & & \\
\hline 1924 & 157 & & 50.833 & & & & & & \\
\hline 1936 & 196 & & & & & & & & \\
\hline 1937 & 192 & & & & & & & & \\
\hline 1938 & 224 & & & & & & & & \\
\hline 1939 & 202 & & & & & & & & \\
\hline 1940 & 193 & & & & & & & & \\
\hline 1941 & 227 & & & & & & & & \\
\hline 1942 & 227 & & 153.561 & & & & & & \\
\hline 1943 & 200 & & 296.060 & & & & & & \\
\hline 1944 & 230 & - & 352.508 & & 17.676 & - & 39.480 & - & 409.664 \\
\hline 1945 & 208 & - & 343.795 & - & 19.769 & - & 35.199 & - & 398.763 \\
\hline 1946 & 168 & - & 302.443 & - & 32.268 & - & 29.832 & - & 364.543 \\
\hline 1947 & 163 & - & 374.830 & - & 24.618 & - & 25.035 & - & 424.483 \\
\hline 1948 & 161 & 5 & 405.686 & - & 22.403 & 1.716 & 27.325 & - & 457.130 \\
\hline 1949 & 134 & 10 & 368.836 & - & 14.541 & 2.523 & 23.291 & - & 409.191 \\
\hline 1950 & 139 & 18 & 359.902 & - & 23.211 & 14.708 & 20.898 & - & 418.719 \\
\hline 1951 & 194 & 19 & 511.076 & - & 41.372 & 11.593 & 8.134 & 44 & 572.219 \\
\hline 1952 & 209 & 5 & 626.464 & - & 22.901 & 1.413 & 1.648 & 400 & 652.826 \\
\hline 1953 & 183 & 3 & 496.890 & - & 16.451 & 528 & 3.204 & - & 517.073 \\
\hline 1954 & 199 & 9 & 607.046 & - & 21.016 & 3.324 & 4.437 & 804 & 636.627 \\
\hline 1955 & 207 & 19 & 646.996 & - & 12.467 & 8.830 & 7.907 & 1.226 & 677.426 \\
\hline 1956 & 176 & 17 & 581.645 & - & 22.903 & 3.391 & 9.826 & 902 & 618.667 \\
\hline 1957 & 161 & 6 & 664.538 & - & 6.248 & 2.603 & 7.376 & 1.106 & 681.871 \\
\hline 1958 & 130 & 9 & 582.121 & -- & 13.753 & 506 & 2.926 & 4.782 & 604.088 \\
\hline 1959 & 154 & 9 & 741.858 & - & 15.582 & 3.882 & 5.509 & 2.029 & 768.587 \\
\hline 1960 & 122 & 24 & 643.948 & - & 1.671 & 26.120 & 3.502 & 3.762 & 679.003 \\
\hline 1961 & 115 & 10 & 662.888 & - & 7.006 & 11.299 & 8.358 & 2.624 & 692.175 \\
\hline 1962 & 128 & 9 & 729.043 & - & 15.045 & - & 14.915 & 5.842 & 765.845 \\
\hline 1963 & 124 & 2 & 623.705 & - & 14.721 & - & 14.284 & 7.177 & 659.887 \\
\hline 1964 & 118 & 16 & 665.296 & - & 13.355 & 38.947 & 13.172 & 6.534 & 737.304 \\
\hline
\end{tabular}


O porto Imbituba na formação do complexo carbonífero catarinense.

continuação

\begin{tabular}{|c|c|c|c|c|c|c|c|c|c|}
\hline 1965 & 125 & 11 & 726.667 & - & 10.652 & 26.072 & 20.648 & 3.523 & 787.562 \\
\hline 1966 & 128 & 10 & 738.570 & - & 6.498 & 26.205 & 15.271 & 5.757 & 792.301 \\
\hline 1967 & 109 & 1 & 745.430 & - & 5.061 & - & 12.335 & 801 & 763.627 \\
\hline 1968 & 103 & - & 832.186 & - & 4.991 & - & 12.753 & - & 849.930 \\
\hline 1969 & 113 & 5 & 869.710 & - & 7.633 & 57.517 & 17.013 & 5 & 951.878 \\
\hline 1970 & 120 & 8 & 835.640 & - & 13.973 & 45.542 & 20.458 & - & 915.613 \\
\hline 1971 & 124 & 7 & 948.220 & - & 12.105 & 30.815 & 18.451 & 1.138 & 1.010 .729 \\
\hline 1972 & 94 & 8 & 677.950 & - & 8.348 & 26.850 & 21.487 & 4.426 & 739.061 \\
\hline 1973 & 106 & 7 & 823.720 & - & 8.030 & 23.745 & 21.921 & 428 & 811.844 \\
\hline 1974 & 103 & 10 & 963.365 & - & 7.390 & 73.165 & 26.881 & - & 1.070 .801 \\
\hline 1975 & 84 & 12 & 829.850 & - & 4.471 & 26.808 & 20.286 & 3.340 & 884.755 \\
\hline 1976 & 83 & 12 & 940.590 & - & 2.362 & 26.861 & 25.160 & 404 & 995.377 \\
\hline 1977 & 71 & 29 & $1.016 .317,00$ & - & 500 & 88.143 & 2.347 & 8.340 & 1.115 .647 \\
\hline 1978 & 92 & 29 & $1.238 .584,00$ & - & 601 & 39.337 & - & 24.559 & 1.303 .081 \\
\hline 1979 & 128 & 25 & 1.621 .256 & - & 57.481 & 69.367 & 5.665 & 33.174 & 1.786 .943 \\
\hline 1980 & 198 & 30 & 2.180 .383 & - & 87.848 & 131.675 & 45.351 & 123.010 & 2.568 .267 \\
\hline 1981 & 305 & 28 & 2.676 .433 & - & 134.824 & 100.065 & 161.731 & 101.889 & 3.174 .942 \\
\hline 1982 & 291 & 30 & 2.240 .585 & - & 180.146 & 151.251 & 374.638 & 4.904 & 2.951 .524 \\
\hline 1983 & 366 & 17 & 3.140 .043 & - & 212.164 & 98.476 & 452.313 & - & 3.902 .996 \\
\hline 1984 & 335 & 37 & 2.749 .128 & - & 240.982 & 180.852 & 670.663 & 1.498 & 3.843 .123 \\
\hline 1985 & 315 & 33 & 2.664 .761 & 39.462 & 261.764 & 79.108 & 751.618 & 5.249 & 3.801 .962 \\
\hline 1986 & 284 & 34 & 2.971 .291 & 107.896 & 225.210 & 63.626 & 741.820 & 2.958 & 4.112 .801 \\
\hline 1987 & 267 & 37 & 2.955 .000 & - & 165.786 & 87.264 & 717.910 & 19.944 & 3.945 .904 \\
\hline 1988 & 197 & 14 & 2.042 .846 & - & 277.148 & 27.129 & 596.230 & 11.563 & 2.954 .916 \\
\hline 1989 & 127 & 29 & 1.284 .995 & - & 200.158 & 36.347 & 398.478 & 126.767 & 2.046 .745 \\
\hline 1990 & 105 & 45 & 795.439 & - & 137.734 & 144.424 & 288.816 & 174.629 & 1.541 .042 \\
\hline 1991 & 78 & 51 & 649.018 & - & 101.841 & 43.872 & 110.497 & 24.380 & 929.608 \\
\hline 1992 & 47 & 187 & 193.461 & - & 16.859 & 137.183 & 167.838 & 115.020 & 630.361 \\
\hline 1993 & 18 & 279 & 16.156 & 31.150 & 1.692 & 285.009 & 68.447 & 144.001 & 546.455 \\
\hline 1994 & 21 & 310 & - & - & 2.510 & 422.001 & 103.009 & 232.367 & 850.887 \\
\hline 1995 & 28 & 240 & - & - & 18.759 & 471.294 & 196.783 & 497.762 & 1.184 .598 \\
\hline 1996 & 23 & 53 & - & - & 2.930 & 157.298 & 75.509 & 148.881 & 384.618 \\
\hline 1997 & 30 & 106 & - & - & 31 & 206.391 & 121.276 & 247.960 & 575.658 \\
\hline 1998 & 27 & 70 & - & - & 13 & 261.100 & 129.879 & 539.472 & 930.464 \\
\hline 1999 & 42 & 71 & - & - & 11.388 & 188.122 & 140.284 & 748.413 & 1.088 .207 \\
\hline 2000 & 17 & 71 & - & - & - & 106.406 & 140.745 & 908.897 & 1.156 .048 \\
\hline
\end{tabular}

Fonte: Para os anos de 1918 a 1943: MORAES, Fábio Farias de. O porto carvoeiro na formação do complexo carbonífero catarinense: a disputa entre Laguna e Imbituba. Criciúma: UNESC, 2006. (Monografia de graduação). Para os anos de 1944 a 2000: Dados fornecidos pela Companhia Docas de Imbituba. 
Alcides Goularti Filho

Anexo 2: Mapa ferroviário e portuário de Santa Catarina

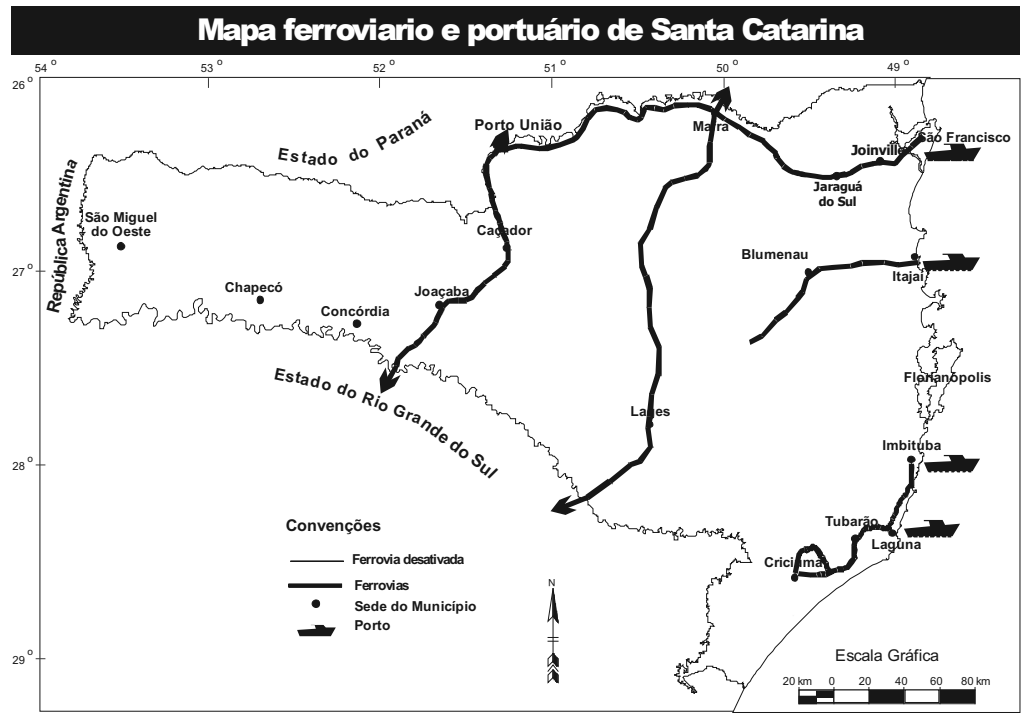

Fonte: GOULARTI FILHO, Alcides. Formação econômica de Santa Catarina. Florianópolis: Cidade Futura, 2002.

Anexo 3: Mapa do complexo carbonífero catarinense

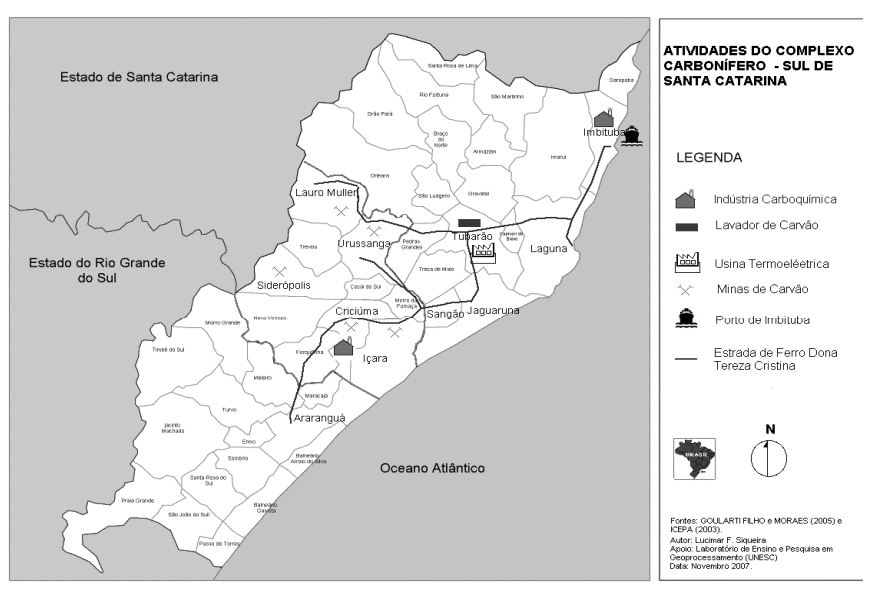


O porto Imbituba na formação do complexo carbonífero catarinense.

\title{
O porto de imbituba na formação do complexo carbonifero catarinense
}

\author{
Alcides Goularti Filho
}

Resumo: O objetivo deste artigo é descrever e analisar a inserção do porto de Imbituba no complexo carbonífero catarinense com unidade de escoamento da produção de carvão da região sul-catarinense para o Sudeste brasileiro de 1880 a 2000. O texto está dividido em seis tópicos que narram desde a criação do porto na Enseada de Imbituba por uma companhia inglesa que estava construindo a Estrada de Ferro Dona Tereza Cristina, em 1880, e que logo é abandonado pela mesma companhia. Analisa a forma como foi adquirida a área portuária e a aprovação do privilégio para explorar os serviços, dado ao empresário do Rio de Janeiro, Henrique Lages. Também será dada ênfase na disputa com o vizinho porto de Laguna para consolidar-se como o único porto carvoeiro do país. E, por último, destacaremos a consolidação do porto de Imbituba como o porto carvoeiro nacional após 1945, seguindo da sua consolidação e desmonte parcial em decorrência da crise no setor carbonífero iniciada em 1990. Nas reflexões finais será apresentada uma proposta de periodização para estudos do porto de Imbituba.

Palavras-chave: Porto; Carvão; Santa Catarina; História; economia.

Abstract: The aim of this paper is to describe and analyze the insertion of the port of Imbituba in complex with Catarina coal unit for disposal of coal production from the south-east to the Santa Catarina Brazil from 1880 to 2000. The text is divided into six topics that recount since the creation of the port of Ensenada Imbituba by an English company that was building the Railway Dona Tereza Cristina in 1880, and 
which is soon abandoned by the same company. Looks at how you acquired the port area and approval of the privilege to operate services given to the holder of Rio de Janeiro, Henrique Lages. Would also be placed in the dispute with the neighboring port of Laguna to consolidate itself as the only port coal dealer in the country. Finally, we will highlight the consolidation of the port of Imbituba as coal national port after 1945, following its consolidation and partial dismantling as a result of the crisis in the coal industry began in 1990. In the final reflections will be presented a proposal for a timeline for studies of the port of Imbituba.

Keywords: Port; Coal; Santa Catarina; History; Economy.

Recebido: 29/03/2010

Aprovado: $17 / 11 / 2010$ 


\section{Ensaio}

